\title{
Determination of the Constitutive Relation Parameters of a Metallic Material by Measurement of Temperature Increment in Compressive Dynamic Tests
}

\author{
R. Guzmán • J. Meléndez • J. Zahr • \\ J.L. Pérez-Castellanos
}

Published online: 14 July 2009

(C) Society for Experimental Mechanics 2009

\section{Erratum to: Experimental Mechanics}

DOI: $10.1007 / \mathbf{s} 11340-009-9223-z$

\section{Introduction}

Thermal Increment and Plastic Deformation

For an elastic-plastic material in uniaxial stress condition and considering an additive partition of the strain, the equation of energy balance is

$\lambda \nabla^{2} T-\dot{T}=-\frac{\beta}{\rho \cdot C_{p}} \sigma: \dot{\varepsilon}^{p}+\frac{\alpha}{\rho \cdot C_{p}} \frac{E}{(1-2 v)} \operatorname{Tt} \operatorname{tr}\left(\dot{\varepsilon}^{e}\right)$

where $\mathrm{T}$ is the absolute temperature, $\sigma$ the stress tensor, $\dot{\varepsilon}^{e}$ the elastic strain rate tensor, $\dot{\varepsilon}^{p}$ the plastic strain rate tensor and $\operatorname{tr}\left(\dot{\varepsilon}^{e}\right)$ is the trace of elastic strain rate tensor; $\lambda$ is the thermal diffusivity of material, $\rho$ the mass density, $C_{p}$ the

specific heat, $\alpha$ the coefficient of dilatation, $v$ the Poisson's ratio and $\mathrm{E}$ the Young modulus; $\beta$ is the Quinney-Taylor parameter representing the proportion of plastic deformation energy that becomes generated heat.

In Eq. (1) (equation of energy balance or equation of heat propagation),

$\lambda \nabla^{2} T$
$\dot{T}$

$\frac{\alpha}{\rho \cdot C_{p}} \frac{E}{(1-2 v)} \operatorname{Tt}\left(\dot{\varepsilon}^{e}\right)$

$\frac{\beta}{\rho \cdot C_{p}} \sigma: \dot{\varepsilon}^{p}$ is the heat lost by conductivity, is the temporal temperature variation per unit of volume, is the temperature variation associated with the elastic strain, is the temperature variation associated with the plastic strain.

The online version of the original article can be found at http://dx.doi. org/10.1007/s11340-009-9223-z.

R. Guzmán · J. Zahr · J.L. Pérez-Castellanos $(\bowtie)$

Department of Continuum Mechanics and Structural Analysis, Carlos III University of Madrid,

Avda. de la Universidad 30,

28911 Leganés, Madrid, Spain

e-mail: percaste@ing.uc3m.es

J. Meléndez

Department of Physics, Carlos III University of Madrid,

Avda. de la Universidad 30,

28911 Leganés, Madrid, Spain 